\title{
Integrating food waste diversion into food systems planning: A case study of the Mississippi Gulf Coast
}

\author{
Jennifer S. Evans-Cowley,* The Ohio State University \\ Angel Arroyo-Rodríguez, The Ohio State University
}

Submitted May 28, 2012 / Revised December 22, 2012, February 20, 2013 / Accepted February 20, 2013 /

Published online May 16, 2013

Citation: Evans-Cowley, J. S., \& Arroyo-Rodríguez, A. (2013). Integrating food waste diversion into food systems planning: A case study of the Mississippi Gulf Coast. Journal of Agriculture, Food Systems, and Community Development, 3(3), 167-185. http://dx.doi.org/10.5304/jafscd.2013.033.003

Copyright (C) 2013 by New Leaf Associates, Inc.

\begin{abstract}
Food waste presents a great challenge for the efficiency of food systems and for solid waste management. Many solid waste management strategies can be used for managing food waste in the food system, but their implementation depends on local factors. Strategies must also be modified or designed to accommodate local needs and
\end{abstract}

Evans-Cowley is a professor of City and Regional Planning and associate dean of Academic Affairs and Administration for the College of Engineering at The Ohio State University. Angel Arroyo-Rodríguez is an environmental planner specializing in food waste management with the Ohio Environmental Protection Agency, and a doctoral student in city and regional planning at The Ohio State University. Evans-Cowley and Arroyo-Rodríguez are currently engaged in a regional sustainability planning effort on the Mississippi Gulf Coast, where they are working on regional food system planning. Further information about the Plan for Opportunity can be found at http://www.gulfcoastplan.org

* Corresponding author: Jennifer Evans-Cowley, City \& Regional Planning, The Ohio State University; 275 West Woodruff;

Columbus, Ohio 43210 USA; +1-614-292-5427;

cowley.11@,osu.edu unique circumstances. This paper reports the planning process undertaken in the Mississippi Gulf Coast to develop a food system plan that integrated strategies to manage food waste more sustainably. The planning process was a three-step process that engaged stakeholders in the food supply chain from production, distribution, retail, and consumption through to post-consumption. The article describes the specific steps taken to assess the generation of food waste in the foodshed, engage stakeholders, and develop strategies for food waste diversion and management. It concludes by offering recommendations on how communities can integrate food waste diversion into their food system planning efforts.

\section{Keywords}

food scraps, food system, food waste, Gulf Coast, Mississippi, sustainability

\footnotetext{
Note: This paper is based on work conducted for a U.S. Department of Housing and Urban Development Regional Sustainability Planning grant program supporting regional food systems planning on the Mississippi Gulf Coast.
} 


\section{Introduction}

The Mississippi Gulf Coast is famous for its food culture. Locals and tourists alike delight in eating fresh shrimp, crabs, and oysters. Not only has seafood had a prominent role in the local food system, but the food system itself has shaped the history, culture, and economy of the region for well over a century. In 1890, the region processed two million pounds $(907,000 \mathrm{~kg})$ of oysters and 614,000 pounds $(278,500 \mathrm{~kg})$ of shrimp in canneries in Biloxi. By 1902, this grew to almost six million pounds $(2,700,000 \mathrm{~kg})$ of oysters and 4.4 million pounds $(2,000,000 \mathrm{~kg})$ of shrimp, earning the region the title of seafood capital of the world by 1903 (Nuwer, 2006). While seafood is prominent, the region has had an equally important land-based agricultural tradition. For example, radishes were a beer hall staple in the 1910s and 1920s in the northern United States, leading the community of Long Beach to be known as the radish capital of the world (Society, 2010).

In 2010, the region was awarded a HUD Regional Sustainability Planning grant. As part of the region's proposal, it pledged to focus on the Mississippi Gulf Coast's food system. In part this was driven by the social, economic, and environmental impacts of Hurricane Katrina (2005) and the Deepwater Horizon oil spill (2010) on the seafood industry. While the three costal counties and their 11 cities developed comprehensive plans in the years following Hurricane Katrina, the planning efforts primarily focused on broader rebuilding issues, such as reconstruction of housing, and provided limited focus on social, economic, and environmental issues tied to the seafood industry and the food system (Evans-Cowley, 2011; EvansCowley \& Gough, 2007, 2008; Mississippi Renewal Forum, 2005). An evaluation of the inclusion of food system considerations in 12 of the comprehensive plans revealed that eight of the plans did not include goals or objectives directly related to the food system, and four supported the food system to varying degrees. The evaluative study also found that the food systems considerations, when included, were mainly focused on tourism and economic development and not as strongly focused on environmental protection (EvansCowley, 2011).
Although municipalities' interest in food system planning has grown over the past few decades, this planning still is conducted generally as a separate effort from comprehensive planning. A study of 22 U.S. planning agencies in locations with either a food policy council or active food organization found that planning agencies are only lightly involved in food system planning (Pothukuchi \& Kaufman, 2000). The study found that the planners in those locations perceived food issues as being a rural policy issue centered on agriculture, farms, and food production. The planners in the study also failed to recognize the roles that food processing, wholesaling, retailing, consumption, and food waste disposal have in the food system.

One aspect of the food system that can be argued to be often lightly considered, if not forgotten, during planning is the management of food waste. Food waste is generated at every stage of the food system. During farming and post-harvest handling, food is wasted due to weather, disease, mechanization, selective harvesting to meet specifications, storage conditions, processing, selective packaging, and damage during transportation. Food waste is also generated by retailers, food service establishments, and households as a result of storage conditions, buying improper amounts, food safety regulations, personal taste preferences, and behavior toward food. According to the USDA Economic Research Survey, about 96 billion pounds (44 billion $\mathrm{kg}$ ) of food, or $27 \%$ of the 356 billion pounds ( 161 billion $\mathrm{kg}$ ) of edible food available for human consumption, were lost as food waste at the retail, food service, and household levels in 1995 in the United States (Kantor, Lipton, Manchester, \& Oliveria, 1997). A county-level study found that food waste was generated across production (20\%), processing (1\%), distribution (19\%), and consumption (60\%) (Griffin, Sobal, \& Lyson, 2009). Of the food waste generated, only $27 \%$ was recovered (Griffin et al., 2009). Food waste is part of the residential, commercial, and industrial waste streams. Nationally, food waste is estimated to make up about $14 \%$ of the residential and commercial solid waste stream (U.S. Environmental Protection Agency [USEPA], $2011 b)$. For this reason, diversion efforts are generally conducted by environmental protection pro- 
fessionals engaged in solid waste management planning. Solid waste planning is conducted in the interest of environmental protection, and requirements for preparing solid waste management plans vary by state. In Mississippi, the Nonhazardous Waste Planning Act of 1991 requires each county to prepare a solid waste management plan that must be updated at least once every five years (Nonhazardous Solid Waste Planning Act, 1991). As in the majority of states, in Mississippi the primary focus of these plans is to ensure available capacity for disposal of the waste generated in the county (or relevant planning area) at a properly engineered sanitary landfill. As a way to extend disposal capacity and reduce reliance in landfills, solid waste management plans require the inclusion of waste diversion and reduction strategies, such as recycling (Mississippi Department of Environmental Quality [MDEQ], 1992).

Until recently, efforts have been focused on traditional recyclables (paper, metals, plastics) and not so much on food waste. Recently, several municipalities throughout the United States have developed "zero waste" plans that address the collection and diversion of food waste from the residential, commercial (restaurants, supermarkets, hospitality sector), institutional (schools, universities, hospitals), and industrial (large food processing plants) waste streams. Still, most plans are limited to providing best options for the collection and recycling of food waste through waste management options such as composting. For example, the Zero Waste Strategic Plan for the city of San José, California, delineates strategies for the efficient collection of food waste and diversion for composting and/or biogas recovery for energy (City of San José Environmental Services Department, 2008). In terms of strategies that could be related to the food system, it specifies reducing food packaging and ensuring that any packaging is compostable or recyclable, along with educating about backyard composting and gardening. Although certainly related to the food system, these strategies are mainly aimed at facilitating the management and recycling of food waste and, in the case of backyard composting, reducing the costs of transportation and processing. This illustrates that their focus on finding disposal options limits the ability of solid waste planners to be involved in the comprehensive prevention and management of waste through food system planning. Hence, solid waste plans do not appropriately address all food waste at all stages of the food system.

Of the 12 comprehensive plans evaluated in the Mississippi Gulf Coast, only one mentioned food waste, but it provided no details nor specific policies, tools, or strategies for promoting food waste recovery and diversion (Evans-Cowley, 2011). Each of the three coastal counties prepares its own solid waste management plans. One of the counties adopted an updated solid waste plan in 2009 , and the other two are in the process of updating their plans. The current plans do not include strategies that target food waste diversion. However, Harrison County is in the process of updating its solid waste plan and has included residential food waste diversion programs as an option that citizens can prioritize for inclusion in the plan (Environmental Business Services, 2012).

In this paper, we argue that finding appropriate solutions for managing food waste produced throughout the food system would be easier if food system planners and solid waste management planners were engaged jointly in food waste planning. As considered here, food waste planning entails integrating waste reduction, reuse and recycling strategies into food systems plans in order to make the food system more efficient and sustainable. The HUD funding provided the Mississippi Gulf Coast with a unique opportunity to bring together food system and solid waste planners and begin having conversations around what the sustainability of the region's food system meant and to talk about what happens to food as it enters the different waste streams. The main purpose of this paper is to describe a planning process that seems to be effective, but for which we cannot yet measure accurately its success. This is not unusual in the planning field as most plans take years to implement. We surveyed current policy to gain understanding of the region, but we did not analyze the effectiveness of the policies. We applied this knowledge in guiding the planning process to help determine what new policies might be needed. While analyzing the effectiveness of new policies is 
very important, it cannot be performed yet. However, we feel that our process is very promising and is the first attempt at delineating a planning process for food waste management in the food system.

This case study explains how food waste planning was incorporated during the regional food system planning process, which included a food system assessment, a stakeholder assessment, and a food system plan. The plan, titled Savor the Coast: A Recipe for a Sustainable Coast, includes goals, objectives, and strategies directly and indirectly related to food waste management. We begin the paper with a description of the planning area (foodshed). A discussion of the planning approach follows, including a description of the process for assessing food waste generation in the region, the methods used to engage stakeholders, and the development of the plan. We then present a description of the early implementation of strategies. The paper concludes with a discussion of policy decisions and recommendations for achieving food waste diversion in other communities and regions.

\section{Planning Approach}

This food system planning effort is one component of a more expansive sustainability planning effort focusing on Mississippi's three coastal counties: Hancock, Harrison, and Jackson. However, the food system functions beyond the boundaries of the three counties and any reasonable planning effort should consider how food moves across these boundaries. In other words, it is necessary to define the regional foodshed. The foodshed is defined as the 100 -mile $(161 \mathrm{~km})$ radius from the center of the region designated as the Gulfport-

\section{Figure 1 The Mississippi Gulf Coast Foodshed}

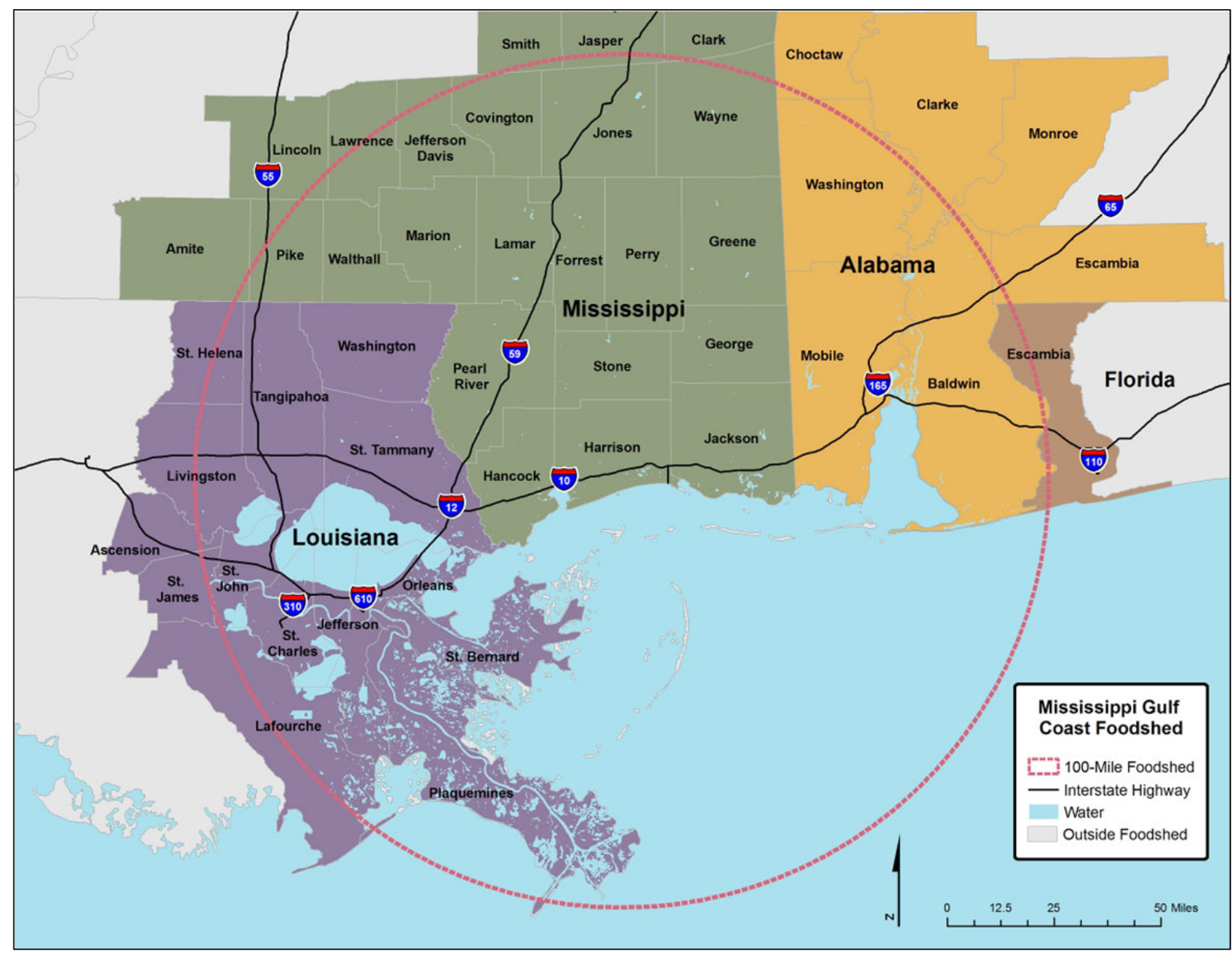


Biloxi area. The 100-mile radius foodshed includes 33 counties and parishes across Alabama, Louisiana and Mississippi, including the waters of the Mississippi Sound and portion of the Gulf of Mexico. See figure 1.

A 12-member food systems subcommittee consisting of local and statewide stakeholders representing all stages of the food system for the Mississippi Gulf Coast guided the planning process. A solid waste planning specialist with the Mississippi Department of Environmental Quality represented the food waste aspect of the food system. The role of the subcommittee is to provide general guidance on the preparation of assessments, identify additional stakeholders, facilitate connections, review documents, and approve final recommendations. The subcommittee serves as a sounding board to help ensure that all work is locally relevant and connected to the region's citizens.

The planning process comprised three steps. The first step consists of a comprehensive assessment of the existing regional food system, including a general assessment of food waste generation and management (Plan for Opportunity, 2011a). The second step, a stakeholder assessment, includes field visits to food waste generators in all stages of the food system, visits to waste processing facilities, and open meetings with food waste stakeholders (Plan for Opportunity, 2011b). The third step entails the development of a strategic food systems plan that integrates sustainable food waste diversion goals, objectives, and strategies (Plan for Opportunity, 2011c). Each of these steps is discussed in detail below.

\section{Food System and Food W aste Assessment}

The purpose of the food system assessment is to describe the current status of the food system. It addresses a variety of topics, including agricultural and aquaculture resources, food distribution infrastructure, food security, the food economy, food waste, and climate change. For the purpose of the discussion here, only the process for assessing food waste will be discussed. The food waste assessment is based on widely practiced solid waste management planning approaches that include identifying waste generators, estimating amounts of waste gen- erated, characterizing waste streams, and inventorying management options. In addition, the assessment includes a review of the regulatory framework relevant to waste management, and potential technologies and market outlets for compost products. The assessment was conducted through literature and information research, phone interviews with solid waste planning stakeholders and in-person interviews with food waste stakeholders. The content of the assessment, considerations during evaluation, and findings are explained below.

\section{Food waste generation assessment. We} based our assessment on waste characterizations and waste audits commonly done in solid waste planning, where the waste stream content is segregated by types of materials, such as glass, plastics, paper, yard waste, food waste, and others, and each type's portion of the waste stream is measured or estimated. Because of constrains in time and resources, however, conducting a detailed assessment of the food waste generated throughout the food system is beyond the reach of this planning process. With this in mind, we decided to focus on three areas: estimating the amount of food waste potentially generated in the three counties; identifying the major generators of food waste in the three counties, with consideration of other generators in the region that could offer opportunity for collaboration; and identifying other organic wastes, such as yard waste and manures, that could enhance food waste management options such as composting.

The food waste that might be generated in the coastal counties can be estimated using the amounts of waste received from these counties at local landfills and national estimates for the amount of food waste in the municipal solid waste stream. The U.S. Environmental Protection Agency (USEPA) estimates that in 2010 food waste represented $14 \%$ of the waste disposed of at landfills (USEPA, 2011b). The USEPA indicates that the percentage of food waste in the solid waste stream has remained at about $14 \%$ for the last several years, so this seems to be an appropriate percentage to apply to regional estimations. On the basis of $14 \%$, 
the three coastal counties generated an estimated 84,700 tons $(76,800$ tonnes) of food waste that were disposed of at the two municipal solid waste landfills in 2009 (MDEQ, 2009b). This estimate is based on data for waste disposed of at the local landfills and does not capture food waste that was composted by homeowners, donated to charities, or managed at farms, as this data is either not collected or easy to extract. In addition, there is no easy way to verify if this estimate reflects the amount of food waste generated locally. However, it is helpful for providing stakeholders with a tangible representation of the amount of food waste that might be generated locally and is still being landfilled.

While diverting all food waste from landfill is a good goal, there is a greater likelihood of seeing substantial diversion results by focusing first on the generators of the largest amounts of waste. Those who generate the largest amounts are more likely to experience cost savings, assuming that sustainable management options are less costly than landfilling. Some of these large generators of waste might have an increased interest in engaging in sustainable practices due to customer expectations. For implementation planning, these large generators also can provide a predictable amount of food waste at a predictable frequency, thus making it easier for waste processors to plan their operations. These large generators include seafood processors, other food processors, grocers, hotels and casinos, government

\section{Figure 2. Seafood Processors on the Mississippi Gulf Coast}

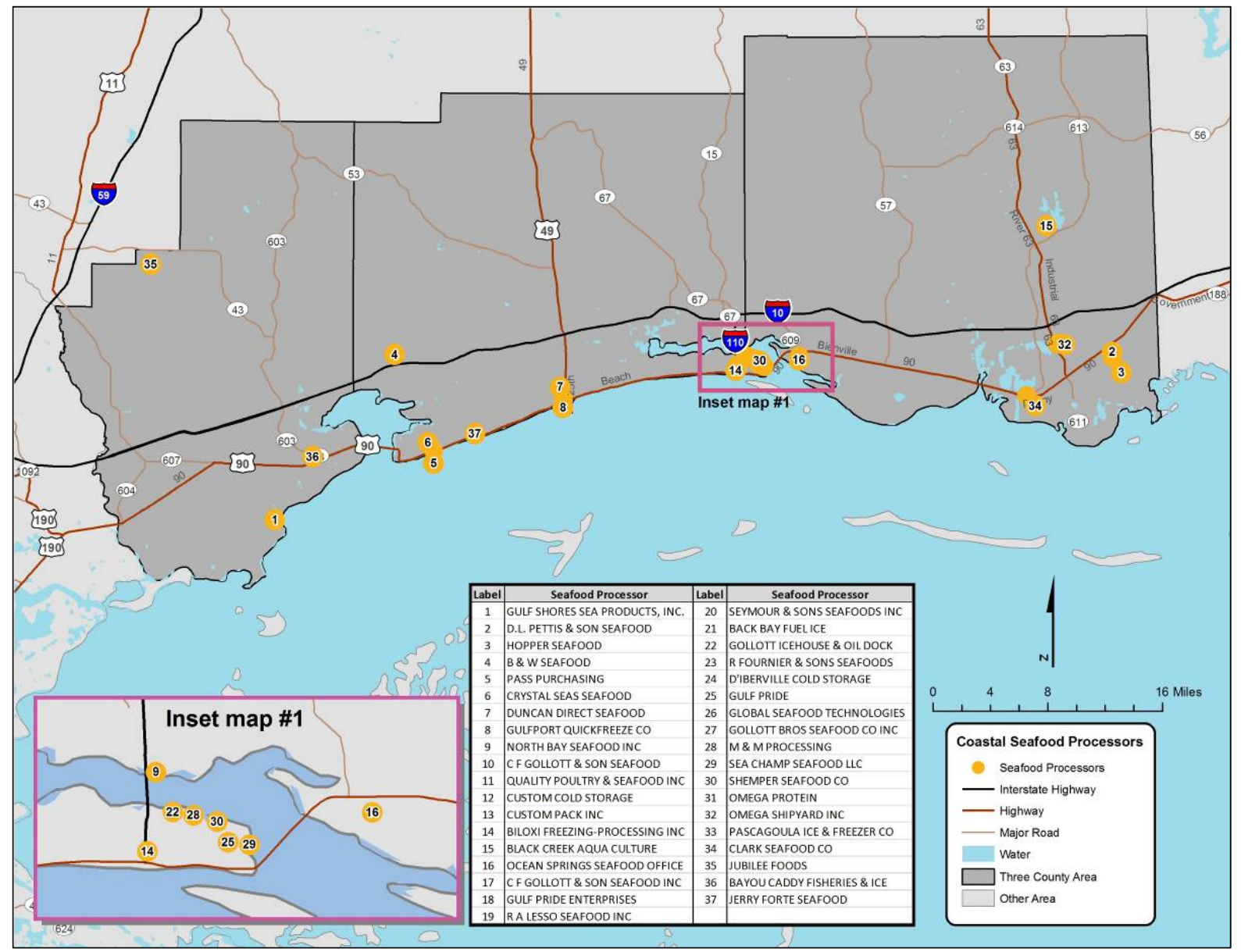

Source: The Plan for Opportunity. 
institutions, and farming operations.

Generators such as restaurants, schools, and higher education institutions have great potential for significant diversion of food waste, but data on waste generation was not easy to find within the time and resources constraints of this assessment. However, these generators were engaged later in the process.

2. Waste characterization. Understanding the estimated amounts and likely composition of the waste stream from the different generators helps to determine suitable management options. The composition of the food waste is greatly dependent on where it was generated. For example, a grocery store will have food that could be donated to food banks and foods in many different types of packaging, while a shrimp processor will mainly have shrimp hulls. Efforts were directed to assess the food waste generation quantities, characteristics, and current management by these specific generators.

In the Mississippi Gulf Coast, seafood processors are significant generators of food processing waste. The three coastal counties have six major types of seafood processors, with over 70 percent producing shrimp or oysters. In 2010, 36 seafood-processing plants were located across the Mississippi Gulf Coast, with 15 seafood processors concentrated just on the Back Bay of Biloxi, as seen in figure 2. Common food processing wastes generated by seafood processing plants include skins or shells, remaining fats, carcasses, items rejected for poor quality, blood, and wastewater, all with varying qualities and quantities (Islam, Khan, \& Tanaka, 2004) (see figure 3). Practically all of the wastes are either inedible or not fit for making other food products for human consumption.

Among the seafood processors, shrimp processors make up the largest waste producers. With an annual shrimp production at 53 million pounds (24 million $\mathrm{kg}$ ) of raw product, which yields just less than 32 million pounds (14.5 million $\mathrm{kg}$ ) of processed shrimp, the industry generates approximately 21 million pounds (10,500 tons, or 9.5 million $\mathrm{kg}$ or 9,500 tonnes) of waste during its seven-month season (Seymour Engineering, 2009). In addition, production fluctuates throughout the season, resulting in fluctuating amounts of waste, which can increase fivefold from April to June (Mississippi State University, 1998). The seasonality of waste production is an important factor to consider when looking for alternatives to disposal. This food processing waste was utilized for animal feed until 2005, when Hurricane Katrina destroyed the feed plant.

Convenience stores, grocery stores, and superstores are generally considered to generate significant amounts of food waste. Published estimates of food waste generated per store are not available, so other estimations are necessary. The average grocery store with 150 full-time employees generates approximately 500 tons (454 tonnes) of solid waste annually (Michel, Drew, Reddy, Forney, \& Trondle, 1995). In this context, the approximately 46 grocery stores in the three-county area will generate an estimated 23,000 tons $(20,865$ tonnes) of solid waste per year. It is important to note that the 46 grocery stores include many convenience stores that employ fewer than 150 full-time employees, so this amount of waste is an overestimate. Furthermore, detailed waste characterizations conducted by a grocery chain at several of its stores found that after cardboard, paper, and plastics are removed for recycling, $75 \%$ to $90 \%$ of the remaining waste is compostable (JFConnolly \& Associates, 2005). Using the conservative estimate of $75 \%$, a typical grocery store generates 375 tons (340 tonnes) of compostable waste per year. For the 46 grocery stores in the region, this could mean that an estimated 17,250 tons (15,650 tonnes) of compostable waste could potentially be diverted from the landfill.

Although this estimate includes wastes other than food waste, it provides an idea of 
how much waste is available to be co-managed through the same process, such as composting. At the time of this assessment, Walmart had started diverting food waste from its seven supercenters and one Sam's Club store in the three counties as well as from stores in adjacent counties and in Mobile, Alabama (see figure 4). Between August and December of 2010, Walmart sent 374 tons (339 tonnes) of organic waste, including food waste, to a composting facility in Franklinton, Louisiana. If this early data is typical of monthly collection, then Walmart alone could divert 900 tons (816 tonnes) of organic wastes annually. This number could grow if Walmart were to include waste from its meat and seafood departments, which was not the case at the time of the assessment (A. Hedrick, Terra Nova Recycling, personal correspondence, March 1, 2011).
The Mississippi Gulf Coast is home to several military bases and federal government agencies that generate large amounts of waste: the John C. Stennis Space Center in Hancock County; the Naval Construction Battalion Center (Seabee Base), the Air National Guard, the Department of Homeland Security, and Keesler Air Force Base (Keesler AFB) in Harrison County; and the Pascagoula Naval Complex in Jackson County. All of these institutional complexes provide daily food services to a large number of military and civilian staff, presenting an opportunity for diverting kitchen (preconsumer) and dining hall (postconsumer) food waste. In any one day, there are approximately 4,000 cadets, 2,870 military personnel, and 1,530 civilian personnel at Keesler (Keesler AFB, n.d.). During the assessment, we found that Keesler was

\section{Figure 3. Workers shucking oysters in a Mississippi Gulf Coast seafood processing plant. The shucking process generates significant waste byproduct.}

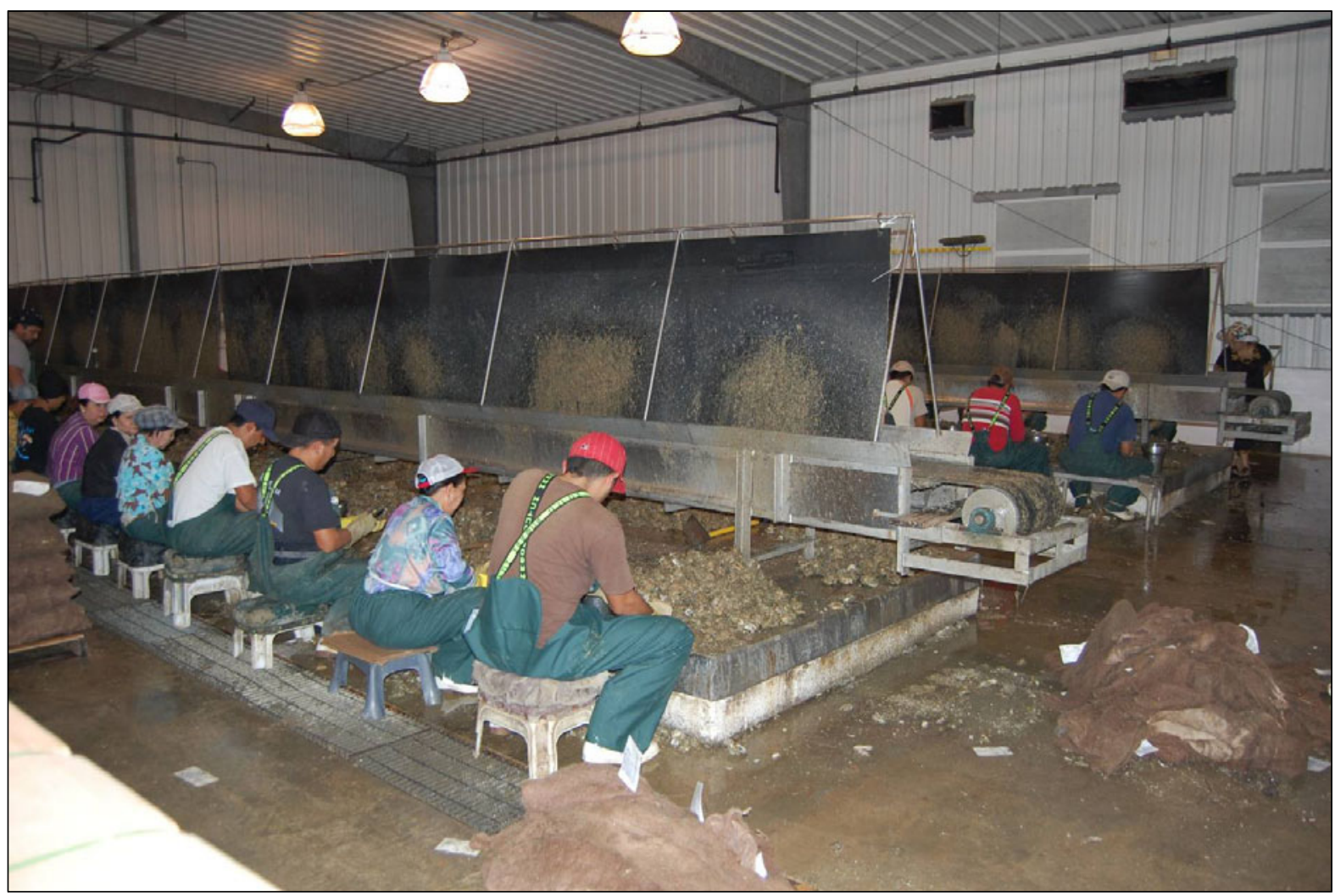

Photo by Jim Melka. 
collecting up to 26 tons (24 tonnes) of food waste each month from its kitchen and dining hall; however, this waste was being sent to the landfill as no other options were available (D. Smith, Zero Waste Solutions/Mark Dunning Industries, personal communication, March 21, 2011). It is expected that similar amounts are generated at the Stennis Space Center and Seabee Base. Together, these represent a potential diversion of 936 tons (849 tonnes) per year.

The Mississippi Gulf Coast is also host to 12 casinos and their associated hotels. In most casinos, food service is the largest function after gaming and is offered during most of the day and night, generating large amounts of preand postconsumer food waste and other organic wastes, such as waxed cardboard, paper containers, and napkins. Just as with grocery stores, there are no accepted published estimates of food waste generation at casinos. This requires us to use data from known food waste generation in limited locations to extrapolate and make estimates for the region. The Ho-Chunk Nation, a tribe in the Black River Falls area in Wisconsin, reports collecting 150 pounds $(68 \mathrm{~kg})$ of food waste a day, or 54,750 pounds $(24,830 \mathrm{~kg})$ or 27 tons $(24$ tonnes) per year, from one of their casinos (Goldstein, 2008). For the 12 coastal casinos, this represents 324 tons (294 tonnes) per year. Some of the local casinos were contacted, but it was not possible at the time to obtain waste data from them to compare and assess if they

Figure 4. Walmart sends its food scraps to Brinson Poultry Farm by the truckload.

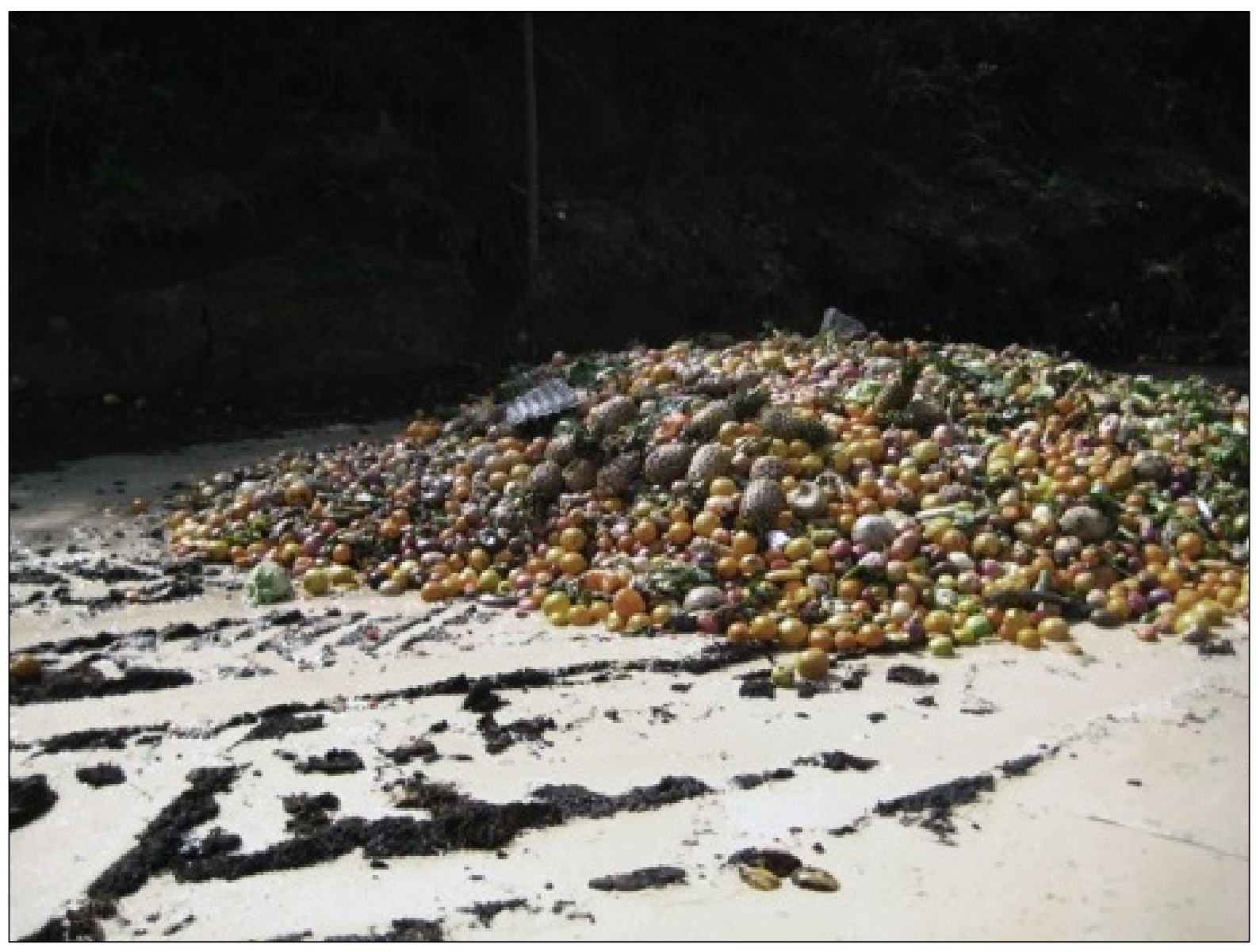

Photo by Megan O'Connor. 
experience similar waste generation amounts. However, these numbers provide a general picture of the potential generation of food waste in the hospitality sector in the three coastal Mississippi counties.

According to the most recent survey of agriculture by the U.S. Department of Agriculture, there are 1,107 farms in the three coastal counties encompassing 105,159 acres (42,556 hectares). Approximately $61 \%$ of the farm acreage is dedicated to woodlands and pasture, $31 \%$ to cropland, and $8 \%$ to other practices. This $8 \%$ includes 143 acres (58 ha) for poultry, 568 acres $(230 \mathrm{ha})$ for cattle and 37 acres (15 ha) for hog farming. None of these farms is regulated as a confined animal feeding operation (CAFO). In addition, 513 out of the 1,107 farms are 10 to 49 acres (4 to $20 \mathrm{ha}$ ) in size. Farm-generated food waste is typically left on the fields, taken back to the same fields for incorporation into the soil, or managed on farm and not disposed at landfills; hence, it is rarely accounted for and data is not available to solid waste planners. In addition, most state solid waste environmental regulations provide full exemptions to agricultural operations, which reduces the possibility of consistently tracking waste generation. On the basis of this information, we concluded that few agricultural operations would generate food waste, and those that do generate it will be very unlikely to send their food waste for disposal off the farm. On the other hand, the farm operations would be likely to accept food waste for composting and land application and would also be a market for compost produced off-farm.

There is certainly a substantial amount of food waste generated by seafood processing, military and government institutions, casinos and hotels in the region. Adding other generators, such as schools, colleges, universities, hospitals, restaurants, and homes, further increases the amount of food waste.

\section{Inventory of disposal and management} options. Guidance on how to divert food waste with a sustainable approach is provided by the USEPA's food recovery hierarchy. The hierarchy focuses on reducing food waste at the source, followed by recovering edible food for feeding people and then animals, using nonedible food waste for industrial uses such as biogas generation, composting, and, as the last option, landfilling (USEPA, 2010a). The inventory efforts tried to identify existing disposal facilities and identify alternative management options.

The prominence of the seafood industry in the Mississippi Gulf Coast food system adds another dimension to the complexity of understanding and managing the food waste generated in the region. Sometimes management solutions are technologically simple and easy to implement, while others require considerable technology and investment. For instance, at the turn of the 19th century, discarded oyster shells would be turned into paving for streets throughout Biloxi (Ellis \& Shambra, 2009). While solutions for oyster shells are relatively simple, alternative uses for the nutrient-rich shrimp byproduct are not as simple to implement. For example, during the early 2000s, a processing factory turned the shrimp waste into other products, such as cat food. However, Hurricane Katrina destroyed the factory in 2005, leaving shrimp processors with the two local landfills as the only alternative for managing their shrimp waste.

At the time of this assessment, no composting facilities were permitted to accept food waste in the coastal three county region. There were only two commercial food waste composting facilities in the foodshed, in Franklinton, Louisiana, and Prentiss, Mississippi, both just over 110 miles from the center of the foodshed (Gulfport-Biloxi). The Prentiss facility, located at a chicken farm, also has an anaerobic digester with biogas recovery that is mainly used to manage the chicken farm's waste. There were no other facilities available that would beneficially use food waste for animal feed or other industrial processes.

There are 14 class I and 22 class II permitted rubbish landfills across the three counties (MDEQ, 2009b). Rubbish landfills receive cardboard, sawdust, and wood chips, 
which can be used as amendments for composting food waste. A rubbish landfill in one of the counties managed by a solid waste management district manages the yard waste received by composting it. The facility location, design and available equipment in the designated composting area would allow for food waste composting once the required permit were obtained.

4. Inventory of waste hauling services. At the time of the assessment, there was only one waste hauling company in the three-county region providing hauling services exclusively for food waste and other organics. This company was hauling food waste for Walmart and Sam's Club superstores, but had capacity to include other local clients (A. Hedrick, Terra Nova Recycling, personal correspondence, March 1, 2011).

5. Regulatory framework. To divert food waste following the USEPA hierarchy, it is important to understand the applicable regulatory framework. Since discarded food is considered a solid waste, the regulatory programs for solid waste implemented by the Mississippi Department of Environmental Quality (MDEQ) are applicable. Current regulations require operators of facilities that compost food wastes to obtain a solid waste facility permit, a process that can take up to two years to complete (M. Williams, Solid Waste Policy, Planning \& Grants Branch, MDEQ, personal communication, March 23, 2011). Acceptance of food wastes at nonagricultural anaerobic digesters for biogas recovery would require a solid waste permit; however, existing solid waste regulations do not properly address this type of facilities.

Beneficial-use determinations and land application permits are two other mechanisms that MDEQ can use to approve alternative disposal of food wastes. These mechanisms, however, are not typically issued for food wastes and are probably useful for a limited portion of the food waste stream. In addition, MDEQ provides support to counties for the preparation of Municipal Solid Waste
Management plans (MDEQ, 2009a), which provides an opportunity to include food waste management strategies.

Federal regulations also affect the options for managing food waste. For instance, the Bill Emerson Good Samaritan Act of 1996 created limited liability for food donations to nonprofits by minimizing liability to donors (Bill Emerson Good Samaritan Food Donation Act, 1996). Ensuring that potential donors are well aware of this legal protection is essential for promoting and increasing donations of food that is still edible. In addition, the U.S. Food and Drug Administration (FDA) has a limited set of policies regarding use of food waste for animal feed. The policies are primarily targeted at stopping the spread of bovine spongiform encephalopathy, commonly known as mad cow disease. Specifically, "the regulation prohibits the use of certain proteins derived from mammalian tissue in feeding ruminant animals" (U.S. FDA, 2010, para. 4). This regulatory requirement can affect the use of some food waste streams for animal feed in some sectors. For example, a grocery store might have to separate mammalian meats from all other food waste if the waste is intended for feed of beef livestock.

The analysis of the food system demonstrated that there is high potential for diverting considerable amounts of food wastes. It also suggested that the hauling, disposal, and management infrastructures, as well as some regulations, can be limiting factors for diversion. However, previous beneficial reuse of some of these wastes revealed a regional preference for more sustainable management options.

\section{Stakeholder Analysis}

The second step in the planning process was a stakeholder analysis. We engaged food waste stakeholders through field visits, interviews and organized stakeholder meetings. We conducted field visits and stakeholder interviews at the places where the food is produced, processed, distributed, sold, consumed, and disposed. This included a poultry farm, a seafood processor, produce distributors, farmers' markets, a brewery, grocery stores, 
restaurants, casino, military bases, food pantry, composting facility, and others. We asked stakeholders about their role regarding food waste, the barriers to diversion, opportunities for sustainable management, and their waste management needs in general.

We organized a food waste stakeholders meeting at a central location. In addition to inviting the stakeholders representing the sectors we had visited and interviewed, we also invited representatives from the various state and local government agencies, nongovernmental organizations, and academia. Participants included farms, military bases, local solid waste planning authorities, food banks and pantries, restaurants and members of the hospitality sector, educators, extension agents, federal and state environmental regulatory agencies, local governments, regional planning agencies, and organic waste haulers, among others.

During the first part of the meeting, we introduced stakeholders to the general food system planning effort for the region and the USEPA's national efforts for food waste diversion, and reviewed current management practices and technology. The purpose of this introduction was to illustrate how the food system gives commonality to such a diverse group of stakeholders while also ensuring that all participants had a basic knowledge of common food waste management practices. The second part of the meeting was a guided, open forum during which we asked stakeholders to share their understanding of the importance of diverting food waste, the role their organizations have in food waste diversion and the food system, the opportunities that food waste diversion offers to the region and their specific sectors, barriers to these opportunities, and potential solutions.

All stakeholders expressed great interest in food waste diversion and quickly identified benefits for both their sectors and the region. In general, stakeholders were well aware of the environmental benefits of diverting food waste, such as extending the capacity of landfills and reducing the generation of greenhouse gases, but they also indicated other benefits. For example, the hospitality, grocery, and institutional sectors considered the potential to reduce disposal costs by diverting to beneficial and less costly options as a significant benefit. The hospitality and grocery sectors expressed that disposal cost avoidance can increase profit margins. While seafood processors had high interest in cost avoidance through environmentally sensitive solutions, the hospitality sector, regulatory agencies, and local governments were very interested in diverting seafood waste from landfills due to concerns with odors caused by this waste at the local landfills. Most local stakeholders indicated that on occasion, odors are detected up to a few miles away. Not only are the odors a nuisance to residents, but they felt that odors can also negatively affect tourism. Food banks and pantries considered diverting food that is still edible to be an opportunity to extend their resources and meet demand for food. Stakeholders indicated better utilization of food resources to reduce food insecurity by donating edible food and by using food waste for sustainable agricultural practices as the main benefit and the top priority for the region.

Regarding barriers to diverting food waste, stakeholders noted that while extending landfill capacity is a motivating factor in other parts of the country, it is not a factor in the region because there is ample landfill capacity for the foreseeable future and landfill disposal fees are currently relatively low. Despite the relatively low disposal fees, cost avoidance is still a motivating factor for several sectors. One important barrier is the lack of other disposal options, such as composting facilities, animal feed manufacturers, and biogas recovery. The distant location of existing options results in transportation costs that are not competitive with the local landfill fees. Prohibitive or discouraging regulatory frameworks were also identified as a major barrier and the probable reason that there were no other existing options for management of food waste in the region. Stakeholders from solid waste planning agencies and local and state government expressed that the permitting requirements for composting facilities were established for facilities that require more stringent oversight than should be required for food waste composting. Likewise, a proposed ordinance by a coastal municipality would allow backyard composting of yard waste, but it specifically prohibits the addition of food wastes. Adjustments to existing regulations could allow or encourage new waste handling facil- 
ities in the region, create jobs and products, and provide new waste management options, all of which were potential benefits identified by stakeholders. Involving government stakeholders in further dialogue, as suggested during the stakeholder meeting, could help mitigate regulatory barriers.

Stakeholders identified the creation of financial incentives as a necessary step in changing the way the region handles its food waste. Kick-starting innovation with tax incentives, grant programs, or other investments could support new projects and push the region's waste management in a new direction. In addition, stakeholders recognized cost avoidance as a financial incentive, and considered general efforts that result in cost avoidance as a principal incentive-based strategy. Stakeholders want waste management solutions that are economically feasible and sustainable. In addition, they want innovative solutions that reduce waste and address food insecurity by promoting such things as the improvement of soils and community gardening.

A common topic that came up during the food waste stakeholders meeting, as well as during interviews and site visits with other stakeholders, is the psychological or attitudinal barriers relating to waste. Many stakeholders volunteered that since Hurricane Katrina, there has been a good general awareness among Gulf Coast residents about the importance of sustainable practices. Many cited the implementation of curbside collection of residential recyclables as evidence of this increased awareness. However, they feel that there is need for education about the consequences of wasting edible food and actual food waste. Thus the stakeholders identified incorporating education into the public dialogue around food and sustainability as a necessary step for addressing this barrier.

Key strategies were identified that could lead to new partnerships among the stakeholders and help in "closing the loop" of food waste, such as creating communication networks and fostering the exchange of information. Stakeholders are committed and engaged in their respective sectors, but they often do not have the time or resources to seek out or create new collaborations without a framework for doing so. The stakeholders' request to meet again with the planning team as a "food waste stakeholders group" to discuss the findings of the stakeholder engagement process and engage additional stakeholders is evidence of the importance of being able to connect in an organized framework. Three months after the original assessment, we hosted a second meeting during which stakeholders had the opportunity to discuss and provide input on ideas for solutions and strategies.

In addition, a focus group with homeless persons was organized. While the intention of the focus group was to discuss food access issues, the 15 participants quickly identified food waste as a significant problem. They explained that due to the lack of refrigerated storage opportunities, their food often spoils and end up as food waste. This problem is compounded by the region's mostly warm and humid climate, which is conducive to quick spoilage of food. The participants emphatically explained that the food waste not only represents a wasted nutritional resource, but a misuse of the limited economic resources they have. While this food waste might not be in amounts large enough as to affect regional diversion rates, preventing it can be important for changing attitudes toward food waste.

\section{Food Systems Plan}

The third step in the planning process was to develop the actual plan document, Savor the Coast: A Recipe for a Sustainable Coast. We developed a framework to help guide potential solutions based on what was learned through the stakeholders analysis and with the guidance of the food systems subcommittee. The framework includes four goals applicable systemwide. Each goal has specific objectives, and for each objective, there are suggested strategies. The goals and objectives, as well as the related strategies, are presented below.

\section{Goals and Objectives}

Systemwide, stakeholders wanted to support increased access to food, foster connections between stakeholders, strengthen the food economy, and promote environmental health. These four key concepts served as the guiding goals for developing strategies and solutions to increase the sustainability of the food system. 
Food waste diversion is integrated into the objectives under each goal. For example, under goal one - support access to healthy food for all community members - there is an objective to expand food diversion to food banks and food pantries. Goal two is focused on fostering connections between stakeholders, so the objectives related to food waste include amplifying communication among stakeholders and educating consumers about the food system. Under goal three, there is an objective to strengthen the regional food economy to promote economic efficiency through resource reuse. Goal four is to promote environmental health and includes the objectives of increasing awareness of human impacts on the food system and fostering a waste-conscious culture.

\section{Strategies}

We developed 12 strategies for advancing food waste diversion in consultation with stakeholders. These strategies are diverse, resulting in solutions related to access to edible food as well as waste management at the end of the waste cycle. Only 10 strategies are presented below, as we think these could be replicated in any community. The strategies are presented organized by the specific goal they support.

Goal 1: Support access to healthy food for all community members.

1. Amend zoning ordinances to accommodate the food system. Zoning codes could be amended to include urban agriculture with composting activities as acceptable accessory activities, allow sales of produce at community gardens, and allow households to compost their food waste.

2. Create a surplus food-matching service. A surplus food-matchmaking website could be a means for food donors to advertise surplus food available for donation. Food banks, food pantries, and soup kitchens could check the website and claim the available food.

3. Create a community kitchen. Homeless citizens reported food waste as a major issue due to lack of refrigeration and storage facilities.
These citizens proposed creating a community kitchen with storage lockers and refrigeration.

\section{Goal 2: Foster connections between stakeholders.}

4. Establish a regional food policy council. A common concern among stakeholders was their lack of connection to others in the food system. The proposed food policy council would be composed of volunteer members who represent the full range of food system activities: producers, processors, distributors, and waste managers. There would be task forces within the council engaged in working on different projects, such as a Food Waste Task Force.

5. Expand school demonstration projects. In addition to producing healthy foods and educating students, on-site demonstration projects could include food waste diversion and composting projects that utilize food waste from the school.

Goal 3: Strengthen the regional food economy.

6. Use vacant lots for community gardens. Allowing and encouraging these community gardens to compost could provide a viable alternative for diverting food waste, producing compost to improve the gardening soils. This alternative becomes more effective if the gardens are allowed to accept food wastes from outside the community garden premises.

\section{Goal 4: Promote environmental health.}

7. Launch a renewable-energy technology innovation investment strategy. There are numerous opportunities to reduce energy consumption throughout the food system. For example, food waste can be converted to energy through anaerobic digestion.

8. Institute a Compost Mississippi program. Solid waste management companies and state and local agencies indicated that there is a lack of knowledge about the benefits and science of composting at the individual and household levels. In addition, they indicated that those who were knowledgeable still lacked information and understanding of the existing reg- 
ulatory requirements and financial opportunities. Composting demonstration projects could be established as start-up businesses or as a means to foster a cultural shift toward food waste diversion.

9. Incorporate food waste recovery into public events. Incorporating recycling of traditional recyclables and food wastes during public events would help foster a cultural shift toward turning wastes into resources.

10. Streamline state permitting rules for composting and anaerobic digesters. The regulations governing the permitting process should be changed to streamline the process and encourage the establishment of food waste composting and anaerobic digestion facilities. Regulations for solid waste management, water resources, and agricultural permitting should be coordinated.

\section{Implementation}

There has been significant action forward on five of the 12 strategies in the food system plan directly related to food waste diversion. This is impressive, given that the food system recommendations were accepted by the region's executive committee in September 2011. Below is a summary of the progress on five strategies as of May 2012.

\section{Amend zoning ordinances to accommodate} the food system. An effort is underway by the regional planning agency to create a model zoning ordinance for food that would integrate composting activities.

2. Create a surplus food-matching service. The United Way of Southern Mississippi has offered to expand its volunteer-matching website to also encompass food donation. In discussions with the military, it became clear that the bases in the region were disposing of significant volumes of edible food. Thinking creatively, the military bases and their waste management offices propose to reclassify the excess food as a salvaged item and sell it for a nominal amount to church groups that would collect the food at the base and deliver it to food pantries.

\section{Establish a regional food policy council.} The participants in the food waste stakeholder meetings were enthusiastic about continuing to meet and wanted to ensure that the Food Waste Task Force component of the regional policy council moves forward. The MDEQ volunteered to organize and facilitate quarterly meetings. The meetings have provided opportunities for networking and the group has expanded. For example, a small composting business was able to obtain approval for a food waste composting pilot project and make connections with organic farmers who are currently buying compost from out of state. In another example, the Keesler Air Force Base connected with a company specializing in the collection and transportation of food wastes and, as a result, was able to send its food waste to a composting facility. This newly formed Mississippi Gulf Coast Food Waste Task Force has continued to meet on a quarterly basis.

\section{Institute a Compost Mississippi program.} The MDEQ volunteered to start developing this program with the help of the newly formed Food Waste Task Force. A meeting of the Mississippi Gulf Coast Food Waste Task Force focused on brainstorming ideas for developing initiatives and outreach projects under a Compost Mississippi branding effort.

\section{Streamline state permit process rules for} composting and anaerobic digesters. The MDEQ had identified updating the permitting rules as a state priority. To effectively update the regulations, the department wants to work directly with composting and anaerobic digestion operations in order to create pilot projects to demonstrate how operations could effectively manage some of the more common wastes in the state, such as shrimp processing waste. In January 2012, the department released the Guidance for Pilot Composting Facility Operations, which outlines the process of obtaining approval as a pilot project as an alternative to the current permit process while the regulations are being streamlined (MDEQ, 2012). 


\section{Conclusion}

Planning for the management of food waste is an important emerging issue not only for professionals in planning, food systems, and solid waste management, but also for all other stakeholders in the system. The information resulting from the assessment and the experiences shared by the stakeholders in the Mississippi Gulf Coast shed light on the importance of planning for food waste management as an integral component of a food system. This case study demonstrated that preventing and managing food waste involves the efforts of practically all stakeholders invested in each stage of the food system and that there can be great benefits by integrating solid waste planning into food systems planning.

Importantly, this planning process in the Mississippi Gulf Coast provided evidence of the lack of accurate and tested estimates of food waste generation in some stages of the food system. At the production and processing stages, the seafood industry generally keeps detailed records of how much processing waste is produced as this is customarily provided by their waste haulers. For landbased agriculture, records of food waste generated in the production stage are generally not available. The need for better estimates in the service industry, specially casinos and hotels, was also evident as the project team had to rely on a few studies that have not been replicated yet in other casinos and hotels offering the same regional amenities and catering to the clientele that the Gulf Coast seeks to attract. Research for developing measurement tools better suited to these generators and for developing reliable generation factors is needed to assist planners in undertaking accurate assessments and determining solutions.

The measurement constraints explained above affect not only the assessments and planning for solutions, but also the measurement of the implemented strategies. As a result, success of the strategies might be based on qualitative more than quantitative measurements. To spur interest and demonstrate the need for this research, we consider it is important to raise awareness that the strategies presented in this project can be accepted readily by the community and quickly implemented; hence is important to be able to quantify their effectiveness. We believe these strategies will be effective and it is necessary to have the means and tools to be able to demonstrate their long-term economic, social, and environmental value to the community.

Throughout the stakeholder process, large managed institutions were recognized as valuable starting points for diverting food waste. Hierarchical management and efficiencies of scale mean that new waste practices can be successfully implemented with relative ease in these institutions as compared to, for example, households or independent restaurants. Continuing to engage and highlight interested institutions was considered crucial in changing waste management practices in the region.

In guiding planning efforts of others interested in food waste reduction, there are several key recommendations. To combat the idea that food is a rural issue that is outside the bounds of the jurisdiction, planners should be considering the foodshed as a geographic area not only where foods can be grown (Getz, 1991), but also where food waste can be utilized as a resource. Because of their traditional involvement in economic development and land use issues, planners are in a good position to foster interactions among the different food systems' producers, distributors, and consumers, as well as solid waste managers. Not only is the Mississippi Gulf Coast Food Waste Task Force that emerged from this project an example of this facilitated interaction, but it also demonstrates how powerful the interaction can be in fostering and implementing regional sustainability goals.

Elevating the importance of food waste planning can be achieved through stronger engagement of food system stakeholders. The boundaries of a foodshed planning area can be set arbitrarily based on regional food production and commerce activities. However, the boundaries of the planning areas for solid waste disposal are determined and/or greatly influenced by governmental structures at the state and local level. In this case study, county boundaries demarcate the larger area in which detailed solid waste planning currently can occur in accordance with state law. This fact was not perceived as an impediment by the project planning team, nor was it identified as such by stakeholders, 
but it did require awareness that all solid waste planning stakeholders for each county needed to be engaged. In the case of the Mississippi Gulf Coast, a regional collaboration can take on food waste planning through its regional sustainability planning process. By creating stronger collaborative planning processes that integrate all stakeholders, from the low-income resident to the seafood processor, communities can develop a higher level of interest in planning (Beatly, 1995; Brody, 2003; Innes, 1996; Roberts, 2006). Part of the success of this effort can be attributed to the significant stakeholder engagement and the willingness of these stakeholders to tackle the environmental issues surrounding food waste diversion (Yaffee \& Wondolleck, 1997). The creation of a department of food by cities, regional food policy councils, and full support of food systems by city planning departments have all been suggested as potential means to support stakeholder engagement around food systems planning (Pohukuchi \& Kaufman, 2000). As demonstrated here, all of these can also serve as means to support planning for food waste diversion.

There are a number of existing regulatory measures and policy tools that could limit food waste diversion. At the state level, environmental and food safety and health regulations must be evaluated for their support of food waste diversion efforts and revised as needed. Regulations on backyard and large-scale composting and biogas facilities should also be evaluated to ensure that they meet their intended environmental protection goals in innovative and flexible ways. Food safety and health regulations at the state level must ensure that they promote (or at least are not an impediment to) recovery and use of edible foods through donations and similar venues. These are just a few examples of the types of policies and regulations that could be included as part of food waste planning.

Implementing regulations and policies that promote food waste diversion can serve as a cornerstone for significant economic development opportunities. Beyond grants and loans, composting, biogas facilities, and other diversion options can benefit the community. For example, the diversion of food waste from grocery stores and military bases along the Gulf Coast spurred the development of a company that specializes in food waste hauling and pilot projects for composting facilities. Economic development tools to further expand this market could foster and strengthen a local economy based on food waste diversion. An effective regulatory framework and market development incentives that focus on locally driven food waste diversion can support job creation in the food system by allowing businesses involved in food waste management the opportunity to grow (Goicochea \& Arroyo-Rodríguez, 2012).

This paper seeks to share a story of success of not only regional planning for food waste diversion, but also early implementation of the plan. This case study demonstrates the potential of food waste planning for integrating food waste diversion strategies into a regional plan. A robust food systems planning effort will consider all aspects of the food system, including food waste, and make culturally appropriate determinations of which goals and implementation strategies are most appropriate. There is a need for further research to explore the success of implementation strategies that emerge from comprehensive planning efforts as they relate to food waste planning. The Mississippi Gulf Coast provides an example of a region where food waste planning efforts can succeed. With the current sustainability planning effort underway, there is significant promise that regional food system planning will be enhanced.

\section{References}

Beatley, T. (1995). Planning and sustainability: The elements of a new (improved?) paradigm. Journal of Planning Literature, 9(4), 383-395. http://dx.doi.org/10.1177/088541229500900405

Bill Emerson Good Samaritan Food Donation Act, 42 U.S.C. $\int 1791$ (1996).

Brody, S. D. (2003). Measuring the effects of stakeholder participation on the quality of local plans based on the principles of collaborative ecosystem management. Journal of Planning Education and Research, 22, 407-419. http://dx.doi.org/10.1177/0739456X03022004007

City of San José Environmental Services Department. (2008). Integrated Waste Management —Zero Waste Strategic Plan. Retrieved from http://www.sanjoseca.gov 
Daniels, S. E., \& Walker, G. (2001). Working through environmental conflict: The collaborative learning approach. Westport, Connecticut: Praeger.

Ellis, J. B., \& Shambra, J. B. (2009). Images of America: Biloxi. Charleston, South Carolina: Arcadia Publishing.

Environmental Business Services. (2012). Survey Harrison County Solid Waste Management Plan. Retrieved from https://spreadsheets.google.com/ viewform? formkey=dGZMU1FIWFhMQ0JNTGII YnpwNk9hOHc6MQ

Evans-Cowley, J. S. (2011). Evaluating food systems in comprehensive planning: Is the Mississippi Gulf Coast planning for food? Journal of Agriculture, Food Systems, and Community Development, 2(1), 105-126. http://dx.doi.org/10.5304/jafscd.2011.021.009

Evans-Cowley, J. S., \& Gough, M. Z. (2007). Is hazard mitigation being incorporated into post-Katrina plans in Mississippi? International Journal of Mass Emergencies and Hazards, 25(3), 177-217.

Evans-Cowley, J. S., \& Gough, M. Z. (2008). Evaluating environmental protection in post-Katrina plans in Mississippi. Journal of Environmental Planning and Management, 51(3), 399-419. http://dx.doi.org/10.1080/09640560801979667

Getz, A. (1991). Urban foodsheds. Permaculture Activist, 24, 26-27.

Goicochea, J., \& Arroyo-Rodriguez, A. (2012). Food scraps recovery in Ohio. BioCycle, 53(2), 22.

Goldstein, J. (2008). Tribal composting projects across the U.S. BioCycle, 49(5), 24.

Griffin, M., Sobal, J., \& Lyson, T. A. (2009). An analysis of a community food waste stream. Agriculture and Human V alues, 26(1-2), 67-81. http://dx.doi.org/10.1007/s10460-008-9178-1 Seymour Engineering. (2009). Feasibility study for the Seafood Industrial Park (U.S. Economic Development Administration Project No. 04-69-05760).

Innes, J. E. (1996). Planning through consensus building. Journal of the American Planning Association,62(4), 460-472. http://dx.doi.org/10.1080/01944369608975712

Islam, Md. S., Khan, S., \& Tanaka, M., (2004). Waste loading in shrimp and fish processing effluents: Potential source of hazards to the coastal and nearshore environments. Marine Pollution Bulletin, 49(1-2), 103-110.

http://dx.doi.org/10.1016/j.marpolbul.2004.01.018

JFConnolly \& Associates. (2005). Supermarket composting bandbook. Boston: Massachusetts Department of Environmental Protection.
Kantor, L. S., Lipton, K., Manchester, A., \& Oliveria, V. (1997). Estimating and addressing America's food losses. Food Review, 20(1), 2-12.

Keesler Air Force Base [AFB]. (n.d.). Newcomers guide. http://www.keesler.af.mil/newcomersguide.asp

Michel, F. C., Drew, S., Reddy, C. A., Forney, L., \& Trondle, E. (1995). Feedstock opportunity Characterizing supermarket organics. BioCycle, 36(1), 68-70.

Mississippi Department of Environmental Quality [MDEQ] Solid Waste Policy, Planning and Grants Branch. (2004). Evaluation criteria for local solid waste management plans. Retrieved from the MDEQ website: http://www.deq.state.ms.us/

MDEQ Solid Waste Policy, Planning and Grants Branch. (2009a, December). Local solid waste management planning: Guidance to local governments for preparing a comprehensive local solid waste management plan. Retrieved from the MDEQ website: http://www.deq.state.ms.us/

MDEQ Solid Waste Policy, Planning and Grants Branch. (2009b). State of Mississippi status report on solid waste management facilities and activities, calendar year 2009. Retrieved from the MDEQ website: http://www.deq.state.ms.us/

MDEQ Solid Waste Policy, Planning and Grants Branch. (2012, January). Guidance for pilot composting facility operations. Retrieved from the MDEQ website: http://www.deq.state.ms.us/

Mississippi Renewal Forum. (2005). The people. Retrieved April 19, 2007, from http://www.mississippi renewal.com/info/people.html

Mississippi State University Coastal Research and Extension Center. (1998). Waste management options for Mississippi shrimp processors. Retrieved from http://coastal.msstate.edu/publish/Waste $\% 20$ Report \%201998.pdf

Nonhazardous Solid Waste Planning Act, Miss. Code Ann. \17-17-227. (1991).

Nuwer, D. S. (2006). The seafood industry in Biloxi: Its early history, 1848-1930. Retrieved from Mississippi Historical Society's Mississippi History Now website: http://mshistory.k12.ms.us/articles/ 209/the-seafood-industry-in-biloxi-its-early-history1848-1930

Plan for Opportunity. (2011a). Mississippi Gulf Coast food system assessment. Retrieved from http://www.gulfcoastplan.org/wp-content/ uploads/2011/12/Food Assessment-WebQuality.pdf 
Plan for Opportunity. (2011b). Mississippi Gulf Coast food system stakeholder analysis. Retrieved from http://www.gulfcoastplan.org/wp-content/ uploads/2011/12/Food Stakeholders-AnalysisWeb-Quality.pdf

Plan for Opportunity. (2011c). Savor the coast: A recipe for a sustainable coast. Retrieved from http://www.gulfcoastplan.org/wp-content/ uploads/2011/12/Food_Savor-The-Coast.pdf

Pothukuchi, K., \& Kaufman, J. L. (2000). The food system: A stranger to the planning field. Journal of the American Planning Association, 66(2), 113-124. http://dx.doi.org/10.1080/01944360008976093

Roberts, P. (2006). Evaluating regional sustainable development: Approaches, methods and the politics of analysis. Journal of Environmental Planning and Management, 49(4), 515-532. http://dx.doi.org/10.1080/09640560600747786

Society, L. B. (2010). Welcome to historic Long Beach, Mississippi. Retrieved February 2, 2011, from http://lbhistoricalsociety.org/

U.S. Environmental Protection Agency [USEPA]. (2010a). Reducing food waste for businesses. Retrieved April 29, 2013, from http://www.epa.gov/wastes/conserve/foodwaste/
USEPA. (2010b). Waste Reduction Model (WARM). http://www.epa.gov/climatechange/wycd/waste/ calculators/Warm home.html

USEPA. (2011a). Greenhouse Gas Equivalencies Calculator. http://www.epa.gov/cleanenergy/ energy-resources/calculator.html

USEPA. (2011b). Text version of municipal solid waste charts: Total MSW generation, 2010. Retrieved on April 30, 2013, from http://www.epa.gov/wastes/facts-text.htm

U.S. Food and Drug Administration [FDA], Inspections, Compliance, Enforcement, and Criminal Investigations. (2010). CPG Sec. 675.400 Rendered Animal Feed Ingredients. Retrieved from http://www.fda.gov/ICECI/ComplianceManuals/ CompliancePolicyGuidanceManual/UCM074717 Yaffee, S., \& Wondolleck, J. (1997). Building bridges across agency boundaries. In K. A. Kohm \& J. F. Franklin (Eds.), Creating a forestry for the 21st century (pp. 381-396). Washington, D.C.: Island Press. 